\title{
Glosse
}

\section{Mit E-Health gegen die Non-Adhärenz}

_ Wenn jemand, obwohl er die 70 Jahre überschritten hat, nicht mindestens fünf verschiedene Medikamente einnimmt, gehört er mittlerweile zu einer vom Aussterben bedrohten sozialen Randgruppe. Der Trend zu einer solchen Polypharmazie ist ungebrochen, obwohl Experten in Sachen Pharmakologie uns immer wieder auf die Risiken dieses therapeutischen Eifers hinweisen; denn dann, wenn bei einem Patienten fünf klassische Erkrankungen vorliegen und wir diese alle leitliniengerecht behandeln, besteht eine große Chance, ihn damit umzubringen.

Die einzige Möglichkeit für den Patienten, sich dem zu entziehen, ist eine konsequente Non-Adhärenz, von der wir Ärzte oft gar nichts mitbekommen. Ja wir glauben sogar, dem Patienten ginge es so gut, weil er alles treu und brav einnimmt. Wer allerdings als Patient nicht so klug oder mutig ist und alles schluckt, landet nicht selten als vermeintlich Sterbender in einer Klinik, wo dann bei infauster Prognose alles weggelassen wird. Und siehe da, nach einigen Tagen nimmt der Patient sein Bett und geht wundersam geheilt nach Hause. Im offiziellen Mediziner-Jargon spricht man von einem „Lazarus-Syndrom".

Doch der nicht selten lebensrettenden Non-Compliance will man jetzt zu Leibe rücken und zwar in Form einer gemeinsam von Krankenkassen und Apothekern entwickelten digitalisierten Überprüfung der Einnahmetreue. Dazu hat man eine intelligente Pillendose entwickelt. Sobald eine Tablette nicht eingenommen wird, meldet sich das Handy mit einer entsprechenden Aufforderung. Diese smarte Art, jemandem seinen gutgemeinten Willen aufzuzwingen, ohne Gewalt anwenden zu müssen, nennt man Nudging. Ein solches zartes An-

\section{Sprint-Intervalltraining}

\section{Kardiometabolisch fit in zehn Minuten}

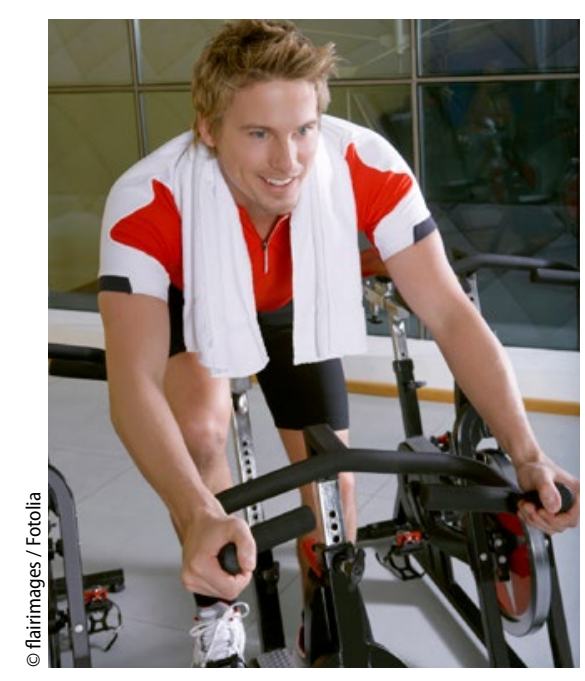

stupsen erfreut sich heute überall großer Beliebtheit, sogar bei politischen Vorhaben. Warum also nicht auch in der Medizin? Doch wenn ein Patient auf diese Art des vorsichtigen Erinnerns nicht reagieren sollte, so tritt die zweite Stufe des Alarmplans in Sachen Adhärenz in Kraft. Jetzt wird dem Patienten ein Roboter quasi als Gouvernante zur Seite gestellt, ob er will oder nicht. Dieser nimmt die Darreichung der Tabletten in die Hand. Dann gibt es kein Entrinnen mehr! Dr. Peter Stiefelhagen

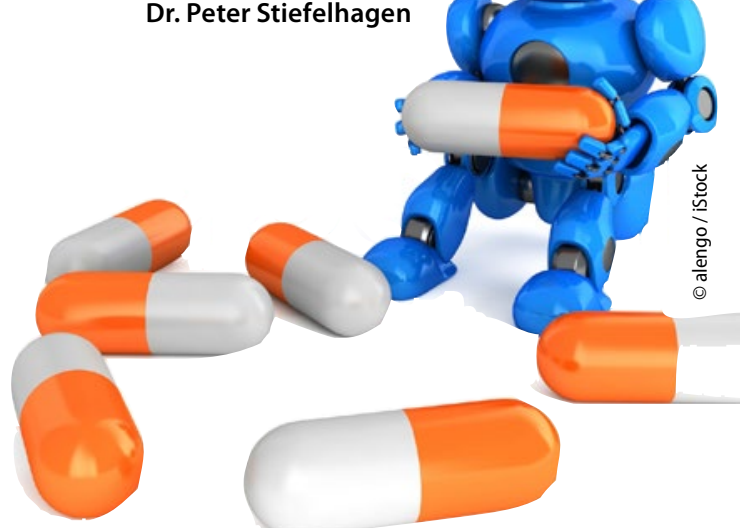

Eine weitere Gruppe absolvierte ein traditionelles Training bei mäßiger Intensität: dreimal wöchentlich für $45 \mathrm{Mi}$ nuten bis zu einer Herzfrequenz von $70 \%$ des Maximums. Eine dritte Gruppe bildete die Kontrollgruppe und trainierte nicht.

Tests nach zwölf Wochen ergaben, dass das intensive Sprinttraining die Männer kardiometabolisch ebenso ertüchtigte wie das traditionelle Training. So stieg die maximale Sauerstoffaufnahme in beiden Gruppen um 19\%, während sich in der Kontrollgruppe keine signifikanten Veränderungen ergaben. - rb - Gillen JB et al. PLoS ONE 11(4): e0154075 